\title{
Sulfur/hollow Carbon Nanofiber Composite as Cathode Material for Lithium-Sulfur Batteries
}

\author{
Yan Yuan*, Zhao Fang, Manbo Liu
}

School of Metallurgical Engineering, Xi'an University of Architecture and Technology, Xi'an 710055 *E-mail address: lingyi21@126.com

doi: $10.20964 / 2017.02 .27$

Received: 7 November 2016 / Accepted: 11 December 2016 / Published: 30 December 2016

Hollow carbon nanofiber was selected as the conductive matrix for elemental sulfur. The influences of preparation method and sulfur content on the structure and properties of the composite were investigated. It is found that the treatment process is inclined to produce large-sized sulfur particles accompanied by severe agglomeration. On the contrary, uniform distribution and compact contact can be established between sulfur and carbon for the composite based on liquid phase precipitation and appropriate sulfur content. The hollow nanofiber material with superior conductivity, abundant holes and good mechanical property, constructs a highly-conductive, porous and stable three-dimensional framework, promoting the electrochemical performances of lithium sulfur batteries.

Keywords: sulfur carbon composite; hollow carbon nanofiber; liquid phase precipitation; lithium sulfur battery; electrochemical performance

\section{$\underline{\text { FULL TEXT }}$}

(C) 2017 The Authors. Published by ESG (www.electrochemsci.org). This article is an open access article distributed under the terms and conditions of the Creative Commons Attribution license (http://creativecommons.org/licenses/by/4.0/). 